\title{
Premature Ventricular Contractions Causing Sinus Arrhythmia and Alternating P-R Prolongation
}

\author{
MICHAEL KUHNE, M.D., FRED MORADY, M.D., and KRIT JONGNARANGSIN, M.D. \\ From the Division of Cardiovascular Medicine, University of Michigan Health System, Ann Arbor, Michigan, USA
}

A 68-year-old male patient was referred because of an irregular heart rhythm. The electrocardiogram (Fig. 1) showed sinus bradycardia with interpolated premature ventricular complexes (PVCs) occurring in a trigeminal pattern.

There are two interesting observations in Figure 1. First, there is an alternating pattern of P-P intervals, with intervals of 1,320-1,340 ms whenever there is a PVC between two conducted sinus beats and longer P-P intervals of 1,420-1,470 $\mathrm{ms}$ when there is not. Secondly, there is also an alternating pattern of P-R intervals, with a P-R interval of $280 \mathrm{~ms}$ fol-

J Cardiovasc Electrophysiol, Vol. 19, pp. 565, May 2008.

Address for correspondence: Krit Jongnarangsin, M.D., Department of Internal Medicine, Division of Cardiovascular Medicine, 1500 E. Medical Center Drive, VAMC 111A, Box 2399, Ann Arbor MI 48109. Fax: 734-845-3270;

E-mail: kritj@med.umich.edu

doi: $10.1111 / \mathrm{j} .1540-8167.2007 .01020 . \mathrm{x}$ lowing a PVC, compared with a shorter P-R interval of 200 $\mathrm{ms}$ in the absence of a preceding PVC.

The alternating pattern of cycle length changes in sinus rhythm is most likely to be caused by baroreceptor-mediated phasic changes in vagal tone that are well-known to cause ventriculophasic sinus arrhythmia in patients with high-grade atrioventricular (AV) block. In this case, whenever there was a PVC between two QRS complexes, the baroreceptor reflex presumably resulted in an increase in vagal tone and a phasic increase in the following P-P interval. The alternating pattern of P-R intervals is explained by concealed retrograde atrioventricular nodal penetration by the PVCs. However, it also is possible that the same changes in vagal tone that affected the P-P intervals also affected atrioventricular nodal conduction, as previously described. ${ }^{1}$

\section{Reference}

1. Skanes AC, Tang AS: Ventriculophasic modulation of atrioventricular nodal conduction in humans. Circulation 1998;97:2245-2251.

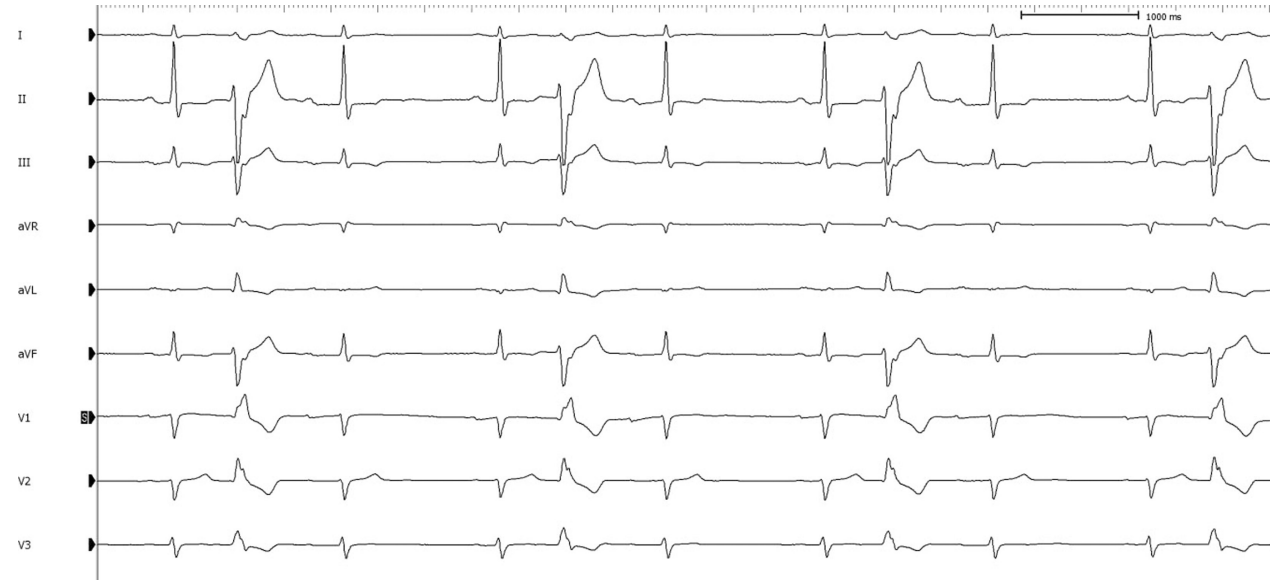

Figure 1. 